\title{
Aspectos antissociais na velhice
}

\author{
Emmanuel Nunes de Souza* (i) \\ Psiquiatra e psicanalista, São Paulo, SP, Brasil
}

\begin{abstract}
Resumos: Segundo Winnicott, a tendência antissocial tem por etiologia uma deprivação que ocorre quando está se dando a fusão entre os elementos instintuais e motores. A desfusão desses elementos resulta num prejuízo no desenvolvimento criativo das relações objetais e na expressão da agressividade. A tendência antissocial se manifesta através de um transtorno no ambiente, por meio da mentira, do roubo e da destrutividade. Neste artigo, apresento um caso clínico em que surgiram comportamentos antissociais numa pessoa idosa e como se constituiu o setting terapêutico para seu tratamento. Por fim, o texto discute se a etapa da vida que se conhece por velhice, por se apresentar amiúde com decadência física e declínio instintual, não causaria nos indivíduos uma deprivação que se expressaria por meio de múltiplos transtornos, normalmente percebidos como manifestações da mera velhice e que, na verdade, poderiam ser mais bem entendidos como expressão de uma tendência antissocial.
\end{abstract}

Palavras-chave: tendência antissocial, velhice, psicoterapia, Winnicott.

\section{Introdução}

O que pretendo pôr em discussão neste texto é se determinados comportamentos aceitos como parte do que se percebe como "mera velhice" podem ser vistos como manifestações do que Winnicott chamou de tendência antissocial (1987/2012) e, sendo isso verdade, quais as implicações no contexto de atendimento em psicoterapia para esses pacientes.

É comum falar-se na autoindulgência dos idosos, em alguma perda de capacidade para o envolvimento e no enfraquecimento do sentimento de culpa. Certa irritabilidade, impaciência e egoísmo são facilmente atribuídos à condição de idade avançada, como se fossem características intrínsecas dessa fase da vida. Os não velhos permitem aos idosos alguma grosseria, numa atitude ao mesmo tempo de reverência e desprezo, concedendo-lhes os direitos que se reconhecem a uma pessoa portadora de uma incapacidade. Será que poderíamos reunir essas percepções da sociedade em relação à pessoa idosa dentro do conceito de comportamentos antissociais?

São muitos os aspectos a serem considerados nesses comportamentos que se atribuem à idade, tanto do ponto de vista da saúde física do idoso, como das condições sociais e familiares em que vive. Minha intenção, contudo, é pôr em foco os elementos que pertencem à psicologia do idoso. Para tal, pretendo utilizar as visões de D. W. Winnicott, Harris Guntrip e Leslie Tizard (1960) e Gilberto Safra (2006a, 2006b, 2006c, 2006d) sobre o período da maturidade e indagar sobre os fatores que poderiam estar relacionados com o surgimento de uma tendência antissocial nessa etapa da vida.

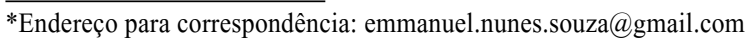

\section{O conceito de tendência antissocial}

Não é difícil constatar que determinado indivíduo apresenta tendências antissociais: sempre há em seu comportamento algum grau de mentira, de agressividade e de ruptura das normas de convívio, e as motivações para esses comportamentos nem mesmo o sujeito que as pratica parece compreender. Na visão de Winnicott (1987/2002, 2012), a pessoa que apresenta tendência antissocial é aquela que - à época em que se espera o estabelecimento da capacidade para o concernimento e em que o ego do bebê está em processo de realização da fusão das raízes libidinais (ou eróticas) e agressivas (ou motilidade) - sofre uma ruptura nos cuidados oferecidos pelo ambiente, cuidados esses que até então eram experimentados pelo bebê como suficientemente bons. Essa perturbação perdura por tempo o bastante para superar a capacidade do ego infantil de lidar com ela. Em função disso, ocorre o desmoronamento das defesas e a reorganização defensiva em um novo modelo de qualidade inferior.

É fundamental assinalar que, no momento em que a privação se dá, o ego infantil já conta, ainda que precariamente, com uma integração que permite ao bebê perceber que a ruptura nos cuidados tem como origem algo que lhe é exterior. A perda de esperança, ocorrida numa época tão primitiva, em que o indivíduo dispõe de recursos muito limitados para lidar com ela, resulta num prejuízo dos processos integrativos que levariam à capacidade de se preocupar com o outro, de experimentar um sentimento de culpa, de alcançar a capacidade para o envolvimento.

É quando o indivíduo tem a percepção (inconsciente) de que o ambiente em que se encontra se mostra confiável e é estável o suficiente para resistir aos 
seus impulsos destrutivos, e quando surge novamente a esperança (inconsciente) de poder ser cuidado de modo a recuperar a experiência do bom ambiente que foi rompida, que os comportamentos antissociais se manifestam com toda a sua intensidade. Nesse sentido, a tendência antissocial é uma organização defensiva que envolve esperança e na qual a criança reclama da privação por meio de comportamentos antissociais dissociados.

Winnicott (1989/2005) nos apresenta duas modalidades fundamentais de atos antissociais: as ligadas à busca do encontro criativo com o objeto, que se expressam pelo roubo e se originam de problemas na apresentação do objeto, feita pela mãe; e as ligadas à busca pela destrutividade, que se expressam pela criação do caos, da agressividade e da ruptura das normas de convívio - estas se ligam mais à figura do pai e afetam sobretudo os meninos (ou o menino dentro da menina). Se a privação original ocorre numa época em que já existe alguma fusão entre as raízes agressivas e as raízes libidinais, os comportamentos antissociais se manifestam por uma combinação das duas modalidades, tanto de furto como de agressividade. Contudo, se a privação ocorre quando existe menos fusão entre essas duas raízes (agressivas e libidinais), a busca pelo objeto e a busca pela destrutividade estão mais separadas uma da outra, e o comportamento do indivíduo apresenta grau maior de dissociação.

\section{Tendência antissocial e velhice}

Pode-se dizer que, na pessoa idosa, vai ocorrendo um progressivo desfusionamento entre as raízes libidinais e as raízes da agressividade? Bem, é forçoso reconhecer que a velhice testemunha a decadência física e o empobrecimento da vida instintual. Mas será que isso representa algo que se possa denominar desfusão instintual motora? E, isso ocorrendo, poderia dar origem ao surgimento de uma tendência antissocial?

A resposta a essa questão depende da visão que se tem dessa etapa da vida. Os autores que mencionei (Winnicott, Guntrip, Tizard e Safra) enxergam o existir humano não só dentro dos registros biológico, psicológico e cultural, mas também a partir de um olhar que contempla o ponto de vista ontológico, ou seja, desde as condições originárias inerentes ao existir humano, que se fazem presentes nos acontecimentos concretos da vida do indivíduo, mas cuja presença não é perceptível, por se situarem para além das referências do tempo e do espaço (do representacional, portanto). Essas questões se referem à precariedade, à solidão e orfandade, à finitude e morte, que estão presentes em toda a vida humana e em cada momento dela, assim como a incompletude e a liberdade. Safra (2006a) afirma que, na maturidade, o indivíduo tem um encontro marcado com as questões ontológicas da existência humana.

Segundo Safra (2006a), em outras etapas da vida, o acesso à percepção do eixo ontológico permanece velado, esquecido pelo indivíduo que, no seu desenvolvimento, se acha ocupado pelas necessidades próprias de cada momento: para o bebê, o constituir-se; para a criança que vai à escola, o socializar-se; para o adolescente, o estabelecer a sexualidade própria; para o adulto jovem, o escolher seu futuro; para o adulto maduro, o viver a família, o trabalho e a sociabilidade. Na velhice, com o declínio da vitalidade, passa a ocorrer uma desconstrução da identidade e do self, que põe o indivíduo face a face com o registro ontológico.

A diminuição do vigor experimentado pela pessoa idosa, diz Safra (2006a), exige dela um novo posicionamento. Sutis modificações vão ocorrendo, de modo que a redução da força física e da disposição pode ser incorporada não necessariamente como um prejuízo desesperante, mas como uma nova forma de estar no mundo. A vida sexual deixa de gravitar em torno da excitação e da performance, e dá lugar à ternura, à busca por uma intimidade amorosa ligada aos aspectos mais tranquilos da existência. A identidade do indivíduo, construída em torno do trabalho, das ações destinadas a alcançar determinadas posições sociais, vai se desfazendo e deixando surgir uma não identidade, em que o centro de gravidade da vida passa a ser a experiência vital em si, e não os possíveis ganhos de projeção social que se possam obter a partir dela. Nesse reposicionamento diante da existência, o indivíduo vai realizando o que Winnicott (1975) chama de "crescer para baixo" (growing downwards); diz o autor: "O sentimento de perda em si mesmo pode tornar-se uma maneira de integrar a experiência" (p. 38). Na maturidade, o self vai "ficando pequeno" para poder passar pelo estreito buraco da morte. Safra (2006a) afirma que tal processo só é possível na medida em que o idoso tenha a capacidade de realizar uma mudança de ancoragem existencial, em que o apego a si, o apego à identidade cede espaço ao experimentar-se a si mesmo como travessia, como passagem. Nessa nova configuração se obtém tolerância em relação às perdas, e a própria morte, nas condições mais felizes, pode ser vista como um bem (Safra, 2006c).

Para que esse novo posicionamento diante da vida seja alcançado, a pessoa idosa vai precisar contar com o apoio da família, das pessoas próximas e do ambiente cultural do lugar onde vive. A possibilidade de contar com essa interlocução e com os cuidados necessários é o que vai tornar possível a realização dessa conquista. Nesse sentido, quando se pensa no lugar destinado ao idoso no mundo contemporâneo, não se pode evitar o pessimismo. A cultura atual (Safra, 2006b) é feita de molde a obstruir as questões ontológicas do campo de visão do idoso. Não há referências ou interlocução em que ele possa se apoiar. O que se encontra é a negação da velhice (nesse sentido, a expressão "melhor idade" contém o eufemismo necessário à camuflagem da realidade). Os projetos para a terceira idade visam afastar o idoso daquilo que de fato vivencia. 
Não encontrando apoio nas pessoas em seu entorno e na cultura a que pertence, o reposicionamento se complica e o delicado processo se degrada. As perdas dão origem a angústias e estas desencadeiam movimentos defensivos de adoecimento em que traumas antigos são reativados e em que mesmo traumas atuais podem surgir (Safra, 2006a). Como reação às perdas, às privações, às deprivações impostas pelo envelhecer, pode ocorrer o desenvolvimento de uma tendência antissocial.

O sofrimento reativo à privação, segundo Winnicott (1967/2005), tem as seguintes características: "Por sofrimento, entendo um estado de confusão, de desintegração da personalidade, um cair para sempre, uma perda de contato com o corpo, uma desorientação completa" (p. 90). Nas queixas do idoso que se decepcionou com as pessoas com quem contava há um quê de "loucura" que não é loucura de fato; ele muitas vezes não se entende e parece viver imerso num estado de confusão e com algum prejuízo na integração da personalidade. Nota-se, na velhice, uma perda de contato com o corpo, que passa a ser o "corpo que não é mais o seu". Nesse sentido, as disfunções físicas situam o corpo como objeto externo ao idoso, não integrado ao self, como algo persecutório que vem do ambiente, fora da área de onipotência do ego.

O mais importante, do ponto de vista winnicottiano, não é tanto a perda ou a falha em si do ambiente suportivo, mas a reação do indivíduo a essa falha, isto é, quando a falha supera sua capacidade de lidar com a situação sem comprometer alguma parte do self. Nesse sentido, quais idosos poderiam desenvolver comportamentos antissociais diante das privações esperadas para a idade?

No capítulo XXV de Da pediatria à psicanálise, Winnicott (1978/2000) afirma: "A tendência antissocial não é um diagnóstico. Não se compara diretamente com outros diagnósticos, tais como neurose e psicose. A tendência antissocial pode ser encontrada em pessoas normais, tanto quanto em neuróticos ou psicóticos" (p. 408, grifo meu). Portanto qualquer indivíduo, dependendo da gravidade (para ele) da ruptura em seu ambiente (ou na unidade do psicossoma), pode desenvolver comportamentos antissociais. No entanto, ao longo de todo o livro Privação e delinquência, Winnicott (1987/2012) desenvolve a ideia de que, antes da época em que a capacidade para o concernimento se estabelece, uma privação que a criança considere significativa pode prejudicar a fusão entre as raízes libidinais e as raízes da agressividade. Nesse sentido, estão mais propensos a desenvolver tendência antissocial aqueles idosos que passaram por privações nesse período da vida e cujos processos integrativos permaneceram precários, precariedade essa que possivelmente foi compensada por características específicas que se organizaram na vida desses indivíduos. Falo aqui da relação com o trabalho, com o casamento, com a família, com os amigos, enfim, da rotina instituída, que pode ter desempenhado uma função protetiva e estabilizadora e que, por ocasião do envelhecimento, apresenta mudanças que nem sempre é possível assimilar.

A partir da noção apresentada por Winnicott (1975) - o sentimento de perda poder ter um papel integrador, ambas as possibilidades para o surgimento de uma tendência antissocial, seja em idosos com histórico de traumas infantis, seja naqueles sem esse histórico, devem ser consideradas plausíveis. Segundo Safra (2006a), a psicanálise clássica superdimensiona a gênese dos traumas durante o período da infância, possivelmente por ser o que ocorre com maior frequência. Entretanto considerar também a possibilidade do adoecimento, mesmo naqueles que passaram bem pela infância, está mais de acordo com o pensamento dos autores que estou considerando.

Declarei no início deste texto que era minha intenção pensar se alguns comportamentos presentes nos idosos, muitos deles encarados como manifestações da mera velhice, poderiam ser vistos como tendências antissociais no sentido winnicottiano. Faço agora alguns apontamentos para tornar mais claro o que aqui se pretende.

Para o entendimento do caso que vou apresentar, será de interesse pensar na relação entre o conceito de tendência antissocial e o tema da transicionalidade. Em determinado trecho do artigo "Objetos transicionais e fenômenos transicionais", em que Winnicott (1975) se refere ao destino do objeto transicional, ele diz:

Nesse ponto, meu tema se amplia para o do brincar, da criatividade e apreciação artísticas, do sentimento religioso, do sonhar, e também do fetichismo, do mentir e do furtar, a origem e a perda do sentimento afetuoso, o vício em drogas, o talismã dos rituais obsessivos, etc. (p. 19, ênfase adicionada).

Ainda nesse mesmo artigo, Winnicott fala sobre como o modo de a criança lidar com a separação (privação) pode influenciar os fenômenos transicionais e relata $o$ "caso do cordão" (p. 31). Nesse caso, um garoto usa exageradamente um objeto transicional (cordões) como parte da negação da ameaça de separação da mãe (que havia de fato ficado distante dele em algumas ocasiões e por períodos de tempo que ele não havia suportado). A situação desse garoto evoluiu para uma perversão e para o vício em drogas. $\mathrm{O}$ recurso ao uso exagerado de um objeto, na sua concretude não simbólica (o que implica a perda do caráter transicional desse objeto), parece ser uma estratégia defensiva muito comum diante da privação ou de ameaça e muito presente nas condições que envolvem o desenvolvimento de comportamentos antissociais. Existe, neste sentido, muito comumente, uma psicopatologia que se manifesta na área dos fenômenos transicionais.

O contexto de psicoterapia que deve ser oferecido a esses pacientes ultrapassa os limites do setting tradicionalmente proposto para o tratamento de pacientes neuróticos. Winnicott chamou de placement (1984/2000) este espaço terapêutico ampliado em que 
é mais importante a vivência intersubjetiva do que a interpretação da transferência e o experiencial do que a simbolização. Este tipo de setting será aqui chamado de manejo terapêutico.

Em "A delinquência como sinal de esperança", título do texto já citado anteriormente, Winnicott faz uma distinção entre delinquência e tendência antissocial: delinquência seria um desenvolvimento desfavorável da tendência antissocial, ou seja, designa o momento em que a esperança já declinou e o indivíduo se apegou aos benefícios secundários oriundos da prática antissocial. O que estou trazendo para a discussão neste artigo se refere apenas à tendência antissocial em idosos, ainda que, muitas vezes, algumas dessas manifestações possam ser impactantes.

Não penso que todo comportamento desagradável nos idosos mereça ser denominado antissocial. Quando, porém, o comportamento surge num contexto em que a esperança foi despertada no idoso; quando, de alguma forma, a situação transtornante criada pelo idoso traz à tona as perdas sofridas e a busca de apoio no ambiente (cuja falha deu origem a determinada organização defensiva), aí sim, penso que a denominação se justifica.

Em relação à aplicação da psicanálise em idosos, é comum ouvirmos que pouco se pode esperar em termos de transformação, que as defesas se enrijeceram e que, na maioria das vezes, o tratamento se traduz numa escuta basicamente de acolhimento. Concordo que esse tipo de atitude terapêutica é positivo e considero que oferecer de fato escuta ao idoso não é algo simples ou banal, e tal procedimento pode, sim, produzir algum resultado positivo para ele. Contudo minha intenção aqui é a de chamar a atenção para inúmeras situações que são criadas pelos idosos e que podem ser mais bem abordadas pela técnica aqui chamada de manejo terapêutico.

\section{Relato de caso clínico}

$\mathrm{V}$., uma paciente que atendo exclusivamente como psiquiatra, perguntou-me se eu não poderia também atender sua mãe, W. Explicou-me que, no último semestre, W. tivera alguns episódios de grave abuso de álcool e que no último deles, ocorrido cerca de dez dias antes, a situação fugira tanto do controle que a família, que se encontrava reunida para um jantar, viu-se obrigada a chamar uma ambulância, que conduziu a mãe de V. até um prontosocorro, onde foi colocada sob contenção mecânica até que seu comportamento voltasse a ser razoável (temia-se que pudesse se ferir em meio à furiosa agitação em que se encontrava). Durante o episódio, W. dava a impressão de não estar consciente e proferia graves imprecações contra seus familiares, cujos conteúdos não me foram relatados.

Perguntei a V. se não seria melhor que um psiquiatra que não conhecesse ninguém da família atendesse sua mãe. Minha paciente esclareceu que aquele não era um pedido seu, mas uma exigência que sua mãe fizera para aceitar o tratamento. Vale ressaltar que eu não tivera até então qualquer contato com W., que sequer fora trazida como tema nas consultas. Eu me limitara ao papel de psiquiatra de V., que havia obtido boa resposta com o uso de medicamentos para depressão. Nossas consultas ocorriam com intervalos de cerca de um mês e meio. Havia, ao que tudo indicava, uma intenção manipulativa nessa condição imposta pela mãe de minha paciente; contudo aceitei o caso: iria encontrá-la para um primeiro atendimento e avaliar melhor o tipo de demanda que me estava sendo apresentado. Registrei, para mim mesmo, que havia sido fisgado pela curiosidade, o que significava que eu fora eficazmente seduzido.

Nesse primeiro atendimento, V. veio acompanhando sua mãe. Disse que esta pedira sua participação na consulta para relatar seu último episódio de embriaguez, uma vez que não se lembrava de nada. Além do relato do ocorrido, que pouca coisa acrescentou ao que já se sabia, V. fez algumas considerações sobre sua mãe: disse que a via como uma mulher forte e batalhadora, que criara os filhos praticamente sozinha (o pai de V. se afastou da família e foi viver com outra mulher num Estado distante, deixando de contribuir tanto material quanto afetivamente) e que, cerca de três anos atrás, se vira forçada a fechar seu ponto de comércio e passara a depender da ajuda dos filhos para sobreviver, situação que, a seu ver, havia lançado sua mãe precocemente numa condição de velhice e dependência que não correspondia à vitalidade que ainda testemunhava nela.

Concluída sua participação, pedi que V. se retirasse; queria ouvir W. expressar-se sem interlocução. Não havia de fato sinais de senilidade nessa senhora. Seus olhos continham algo de maroto e melancólico, em estranhas proporções. Fiquei sabendo que, quando tinha oito anos, uma criança mais velha da família, com a intenção de feri-la durante uma discussão, atirou-lhe na cara que W. era filha adotiva. Os pais, um casal de libaneses, confirmaram: disseram que lhe iriam contar isso e só não o haviam feito ainda porque estavam esperando que a menina crescesse um pouco mais.

W. relata que sempre tivera um desconforto ao comparar a idade dos pais de suas amigas com a dos seus, visivelmente mais velhos. Relata também que estes foram muito carinhosos e cuidaram dela, filha única, de forma muito devotada. A adoção foi feita quando ela tinha um ano de idade e se encontrava num orfanato. Seus pais adotivos, já falecidos na época de nossas consultas, não deram informações sobre seus pais biológicos devido ao desinteresse de W. pelo assunto. A princípio, a surpreendente revelação não trouxe modificações perceptíveis em seu comportamento habitual; na adolescência, porém, atravessou um período de alguns anos de excessos etílicos e consumo esporádico de outras drogas. Por que agia assim, não sabe dizer, assim como não sabe agora por que voltou a agir da mesma maneira: "Sentia um desejo de sair do ar e bebia da forma mais rápida possivel".

Os abusos cessaram pouco antes de W. se tornar maior de idade. Também não soube dizer por que 
cessaram. Casou-se com um homem de sua escolha, sem que estivesse segura se de fato o amava, mas adaptou-se bem ao cotidiano de esposa, mãe e pequena comerciante de roupas. Teve três filhos: duas mulheres (a mais nova é a V., minha paciente) e um homem. Quando W. tinha 36 anos, seu marido deixou o lar e foi morar em Pernambuco com outra mulher. Lá ele constituiu outra família, tornando-se distante da primeira de todos os pontos de vista. W. não se entregou ao desespero; pelo contrário, empenhou-se com muito êxito na tarefa de melhorar a condição financeira dos seus e conseguiu proporcionar aos filhos, com o negócio com roupas, uma vida confortável e logrou fazer o investimento necessário para que concluíssem os estudos de forma adequada. A filha mais velha formou-se arquiteta, casou-se e foi morar com o marido no Rio de Janeiro; o filho do meio abriu uma empresa de importação, prosperou e mudou-se com a sua família para Miami; a caçula, minha paciente, não quis cursar a universidade e é sócia do marido em uma lanchonete.

W. conta que, com os filhos já criados, os negócios começaram a não andar tão bem. Modificações introduzidas no mercado fizeram que seu comércio viesse à falência; o dinheiro que fora guardado foi sendo consumido, e W. teve que ver, surpresa e impotente, seus recursos se esvaírem, até chegar à condição de depender de um rateio entre os filhos para sobreviver.

Tudo isso foi relatado de forma espontânea nesse primeiro encontro e desenvolvido em seus detalhes nos encontros semanais subsequentes, que foram acordados na primeira sessão. Sobre sua exigência de que fosse eu o terapeuta, W. pouca coisa disse, apenas que julgou que preferia tratar-se com alguém que já fosse da confiança de sua filha. Ficou acertado, também, que haveria uma reunião familiar a cada duas ou três semanas, ou quando estivessem todos em São Paulo (seus outros dois filhos moravam fora da cidade). Nossos combinados, todavia, sofreram constantes alterações em função dos acontecimentos: os abusos de álcool se tornariam ainda mais frequentes após o tratamento ter sido iniciado. Antes, eles ocorriam em encontros familiares ou em datas próximas a eles; agora, passaram a ocorrer quando ela estava sozinha em seu apartamento, e os familiares eram avisados do que estava ocorrendo pelos vizinhos, devido aos transtornos que seu comportamento ocasionava.

As sessões individuais não aconteciam com a regularidade que seria desejável, ao menos para mim. De última hora eram remarcadas, por vezes o novo horário também era remarcado, ocorriam cancelamentos ocasionados por toda sorte de contratempos ou mesmo sem explicação ou comunicação prévia. Por outro lado, devido às constantes intercorrências, sessões não agendadas eram feitas com quem estivesse disponível. O clima das reuniões foi aumentando de temperatura. De parte da família, a atitude compreensiva foi cedendo à inconformidade hostil. Dizia-se tudo, reconhecia-se a condição existencial frustrante de W., mas não ficava claro o que os familiares deveriam fazer para contentá-la. Os filhos se diziam vítimas, declaravam que a mãe queria descontar neles seus infortúnios. W., por sua vez, reconhecia que eles não tinham culpa de nada, que eram bons filhos, mas que se sentia uma pessoa inútil e descartável. Assegurava a eles, com apelos veementes, que não queria causar transtornos e que não sabia o porquê dos abusos: eles "simplesmente aconteciam" sem que ela pudesse controlá-los.

O setting ampliado em que o manejo clínico se constituíra continha manifestações de raiva, desencadeada por estímulos discretos e inespecíficos, súplica (pouco consciente) por cuidados, repúdio pela condição de dependência e atitude (inconsciente), paradoxalmente, dependente. Os elementos do conflito nunca chegavam a uma síntese em W.: ela não tinha integração para conviver em sua realidade psíquica com todos esses aspectos. $\mathrm{O}$ atrito contínuo entre esses elementos terminou por produzir expressões cada vez mais graves, até que um incidente mais sério aconteceu: W., embriagada, sofreu uma queda e fraturou o antebraço. No acidente, ela sofreu também importantes escoriações na face. $\mathrm{Na}$ reunião familiar, foi decidido que $\mathrm{W}$. passaria por uma internação psiquiátrica e que, quando tivesse alta, teria acompanhamento terapêutico. E assim se fez: agora W. podia viver a dependência de forma mais profunda.

Grande parte do tempo do manejo terapêutico era consumida na tentativa de que todos se mantivessem informados dos esforços uns dos outros e que nossas ações seguissem numa única direção. Já em meus encontros interpessoais com W., o conflito foi sendo delineado, para nós dois, da seguinte maneira: havia um sentimento de desamparo e de busca de acolhimento que se expressava na forma de um ressentimento em relação aos filhos, embora ela não os julgasse culpados de nada. Por outro lado, W. tinha horror da ideia de depender de alguém, sentia repúdio pelos sentimentos mais ternos e declarou que, paradoxalmente, a melhor fase de sua vida foi a que sucedera ao abandono do marido e na qual tivera que se virar.

Isso foi o máximo que conseguimos: para W., era insuportável manter um conflito dentro de seu psiquismo. Suas atitudes tinham muito de incoerente e irrefletido. Os abusos de álcool, que não cessaram por completo, mas diminuíram sensivelmente com o novo arranjo terapêutico, nunca foram elaborados satisfatoriamente, diria até que nunca eram pensados como se esperaria. Pensar era algo doloroso, o meio deveria pensar por ela, e ela, claro, recusaria o que viesse de fora.

O novo arranjo consistia, além das consultas semanais comigo, na contratação de cuidadoras capazes de oferecer apoio psicológico, em visitas semanais de acompanhante terapêutico e em reuniões a cada duas ou três semanas com a participação de todos os envolvidos no tratamento. Esses encontros eram muito frutíferos, pois proporcionavam a $\mathrm{W}$. a possibilidade de reunir-se a partir do olhar de cada um dos participantes em relação 
a ela. O consumo compulsivo de álcool, que por vezes a levava a perder a consciência, ficou mais raro, mas novas modalidades antissociais foram surgindo, com uma nova índole e atos que despertavam preocupação. Ao mesmo tempo, surgiam tímidos indícios de um gesto autêntico por autonomia. Por exemplo, ela se apropriava do dinheiro, que agora era controlado de acordo com o que era combinado nas reuniões, e desaparecia sem que as cuidadoras se dessem conta. Utilizava o dinheiro, na maior parte das vezes, para adquirir uma peça de vestuário ou um utensílio de que sua casa de fato necessitava. Outras vezes, porém, perpetrava os abusos com todos seus ingredientes dramáticos.

Durante quase dois anos, o tratamento seguiu nesse padrão, para profunda e crescente insatisfação dos familiares, particularmente do filho, que chegou a questionar se tudo que a mãe queria não era apenas um meio de manipular a família da forma mais grosseira, a fim de tornar-se o centro das atenções de todos. Em determinado momento, um acontecimento terminou por ser muito importante simbolicamente pela reação que desencadeou e pelo desfecho que teve. W. havia estourado os pontos da carteira de motorista e formou-se um consenso de que ela deveria sofrer as consequências de sua negligência ao dirigir, e que nenhuma solução fora do estrito termo da lei seria procurada. $\mathrm{O}$ clima das reuniões estava cada vez mais tenso e a atitude indulgente com W. cedia cada vez mais espaço para a raiva que os esforços impotentes provocavam. Já fazia algum tempo, por essa época, que o acompanhante terapêutico vinha tentando convencer-me de que eu deveria solicitar a interdição de W. Ele alegava que isso criaria uma condição melhor para o tratamento; as duas filhas também partilhavam do mesmo ponto de vista. Eu, no entanto, não estava convencido disso pelo simples fato de que $\mathrm{W}$. não apresentava as limitações psíquicas que configuram a necessidade desse instrumento.

Voltando ao acontecimento que representou uma inflexão no tratamento: numa das reuniões gerais, uma das cuidadoras trouxe a informação de que $\mathrm{W}$. voltara a dirigir, e esta não só confirmou o fato como ainda acrescentou que havia "comprado" uma carteira de habilitação de forma ilícita. Aquilo fez transbordar a água que já vinha se acumulando de forma perigosa. A reprovação muito enfática foi geral: de um lado as duas filhas explicitaram sua intenção de interditá-la, pedindo o apoio dos demais; do outro lado ficou o filho, nem sempre presente nas reuniões por morar em outro país, mas que desta vez ali estava e anunciou sua desistência daquela rede de cuidados. Ele manteria suas obrigações financeiras, que julgava justas, mas havia se cansado do comportamento inconsequente da mãe. W., por sua vez, dobrou a aposta: não era o filho ou quem quer que fosse que estava desistindo, era ela quem estava atirando para bem longe os cuidados que vinha recebendo. De forma muito agressiva e indignada, disse que não queria mais ser "pajeada" por ninguém, que não aceitaria mais as cuidadoras e todas as limitações que lhe vinham impondo e que sabia muito bem se virar sozinha. Lembrou ainda uma vez os anos em que sustentou a todos com seu trabalho, se disse farta de tudo que vinha sendo feito em sua ajuda e afirmou que, dali para frente, iria se conduzir de acordo com o que julgasse mais apropriado. Houve muita discussão e acusações mútuas, mas não se chegou a nada razoável na reunião; as filhas terminaram por seguir o filho e se disseram muito cansadas de todo o investimento que vinha sendo feito e frustradas com o comportamento da mãe. E assim se fez: sem que fosse preciso verbalizar, ficou entendido que as coisas correriam soltas até que um novo fato indicasse a necessidade de aquele grupo voltar a se reunir.

Passaram-se cerca de três meses sem que eu tivesse qualquer notícia do desenrolar dos acontecimentos. W., então, entrou em contato para marcar uma consulta. Reapareceu com bom aspecto, embora se queixasse de sintomas depressivos. Medicada, obteve boa melhora e disse estar satisfeita. Faz cerca de dois anos e meio que vem às consultas a cada quarenta ou cinquenta dias. A relação com os filhos foi se normalizando aos poucos. V. também retomou suas consultas e confirmou que as atribulações haviam serenado. Quando pergunto a W. se tem feito uso de bebidas, ela responde que não, que deixou de sentir aqueles impulsos que a levavam aos abusos. Nas consultas, W. e eu conversamos de forma livre, como se fôssemos dois velhos amigos. O que afinal a fez parar de beber? Diz não saber.

\section{Comentários}

Embora o caso exposto não tenha levado a um desfecho plenamente satisfatório (apesar de, no meu entender, o manejo terapêutico ter sido o que permitiu que o conflito pudesse ser vivido pela paciente, graças à sustentação oferecida pelo seu entorno), acredito que, no contexto deste artigo, alguns aspectos relevantes são levantados.

Destaco alguns pontos para discussão.

O primeiro deles é a condição de vida de $\mathrm{W}$. antes da adoção, inteiramente desconhecida. Nenhum dado anterior à adoção é revelado pela paciente ou por seus filhos, e não há ninguém em condições de trazer informações. Pode-se conjecturar muita coisa, mas a obscuridade permanece muito espessa. Que W. foi exposta no passado a grave rejeição é coisa certa, mas não se sabe o grau em que essa rejeição a atingiu. Pode-se falar em uma privação precoce? Não creio ser o caso; apesar da pouca informação, parece mais apropriado pensar numa deprivação. No início da vida, a despeito do que tenha ocorrido, determinado grau de integração foi conquistado por W., afastando o risco de um funcionamento psicótico. Deve-se ter em mente que a percepção que minha paciente desperta em todos à sua volta é a de uma pessoa normal, que teve uma trajetória de vida razoavelmente exitosa.

Em três momentos, o problema da rejeição impactou a vida de W.: quando lhe foi revelado que era 
filha adotiva, quando seu marido a abandonou e quando se tornou dependente dos filhos. Na adolescência, ela teve cuidados psicológicos e tudo pareceu superado ao tornar-se adulta, casar-se, ter filhos e uma boa relação com o trabalho. A rejeição do marido revelou que a relação com ele era menos importante do que a que mantinha com os filhos e com o trabalho. O modo como lidou com a situação pareceu tê-la fortalecido.

Outro aspecto a ser levado em consideração é o entendimento das relações de objeto de W. Quando o sentimento de rejeição dominava a cena, surgia o impulso de beber até que a consciência fosse abolida. Aqui temos uma pessoa, sua relação com um objeto e a alienação como resultado dessa interação. $\mathrm{O}$ objeto bebida não tem valor simbólico, não leva à ilusão criativa, tampouco coloca W. em devir em relação a outros objetos (observe-se a perda do caráter transicional desse objeto). Vemos aqui o uso exagerado de um objeto diante da solidão e ao sentimento de rejeição. Com o uso da bebida, minha paciente conseguiu manter em dissociação tudo que se encontra relacionado ao primeiro ano de sua vida - a rejeição não pôde ser pensada, não pôde ser tomada como conflito intrapsíquico. W. não consegue deprimir, uma integração da rejeição que sofrera no primeiro ano de sua vida com a frágil unidade parcial que conquistou depois da adoção é por demais ameaçadora, e aí entra o uso de bebida, provocando o curto-circuito e mantendo a dissociação.

Os riscos inerentes à integração, que o trabalho analítico poderia conjurar, sempre estiveram presentes para mim, e o trabalho com W. não deveria privilegiar o espaço intrapsíquico, e sim o terreno ampliado do interrelacional. O sentimento destrutivo e até mortífero de rejeição pôde ser vivido na realidade concreta propiciada pelo manejo terapêutico. $\mathrm{O}$ horror em aceitar uma relação de dependência pôde ser experimentado de forma dispersa comigo, com as cuidadoras, com o acompanhante terapêutico e com seus filhos. O uso da agressividade e a busca de uma destrutividade pessoal foram possibilitados pela relação de nutrição proporcionada por esse conjunto de relações. O repúdio teve também lugar, encontrando sua mais alta expressão quando desfez seu compromisso com o arranjo terapêutico, do qual já havia feito o uso de que necessitava.

Algo que procurei destacar - e que não estou certo de tê-lo feito suficientemente - foi certa mudança de caráter nos atos antissociais perpetrados por W. Se antes eram puramente destrutivos e alienantes, com o passar do tempo adquiriram um sentido mais amplo e que apontavam também algo construtivo e no sentido da independência. $\mathrm{O}$ "dinheiro roubado" às vezes era gasto só para W. se embriagar, mas outras vezes era utilizado para a compra de utensílios para a casa e de roupas das quais minha paciente tinha realmente necessidade. $\mathrm{O}$ suborno para obter a carteira de habilitação constituía uma contravenção, mas era também um desejo de autonomia. Essas mudanças nem sempre foram percebidas pelos familiares, que pouco souberam valorizá-las quando lhes chamei a atenção para a questão.

Outro elemento que, a meu ver, teve peso decisivo para o rumo dos acontecimentos foi o fato de que, durante o tratamento, W. se percebeu uma pessoa idosa e se ajustou a essa nova identidade. Com a falência de seu comércio de roupas, minha paciente poderia ter partido para outro empreendimento, mas ela sentiu que não tinha mais a força da juventude para se lançar. O peso da idade veio junto com a condição de dependência financeira em relação aos filhos. W. sentia-se rejeitada pela família, um peso indesejável que os filhos tinham de carregar. Os netos cresceram e desenvolveram seus interesses próprios, entre os quais visitar a avó não estava em primeiro plano. W. sentiu desamparo, solidão e falta de propósito existencial: as privações que sofrera em vários planos não puderam ser vividas dentro de um episódio depressivo (como teria sido mais saudável) devido à ameaça que um movimento integrativo traria à frágil unidade que conquistara.

As perdas causadas pelo envelhecimento fizeram ressurgir em $\mathrm{W}$. a rejeição originária que sofrera; nesse sentido, a tendência antissocial surge como um pedido de ajuda. Não obstante, devido à boa qualidade de seu ambiente suportivo e ao manejo terapêutico oferecido W. pôde realizar o gesto que Winnicott chama de grouwing downwards, o crescer para baixo, e superar a equivalência entre criança abandonada e idosa abandonada. $\mathrm{O}$ transtorno causado no ambiente que a cercava, os atos antissociais que, de algum modo, eram acolhidos pelos familiares (que em nenhum momento deram a impressão de que iriam sucumbir diante dos ataques), a possibilidade de experimentar no plano concreto essas vivências produziram, ao que tudo indica, uma nova acomodação em sua realidade interna, de modo que agora W. parece viver a rejeição vulgar a que estão sujeitas todas as pessoas mais velhas pela sociedade. Com a assunção da velhice, W. pôde realizar a integração que é possível nesse momento da vida, ou seja, assimilar as perdas e passar a viver dentro dessa nova realidade. Quero acreditar que, nesta nova reunião em que as perdas são reconhecidas, W. poderá viver sua condição de incompletude dentro dos referenciais da cultura, partilhando sua condição com milhões de outras pessoas na mesma situação. A impossibilidade de suportar entrar em contato com a rejeição ligada ao primeiro ano de vida, decorrente do horror que tal contato despertaria, tem a ver com o fato de que ali não havia ninguém, nenhum rosto humano que sequer se oferecesse para ser temido, odiado e repudiado.

\section{Considerações finais}

Neste texto, a partir da discussão de um caso clínico, procurei chamar a atenção para a possibilidade de estabelecer uma distinção diagnóstica entre o que pode ser percebido como manifestação daquilo que 
chamei de mera velhice e o surgimento de uma tendência antissocial na maturidade. Foram trazidas à discussão as visões de alguns autores a respeito desse período da vida chamado maturidade e o conceito winnicottiano de tendência antissocial. Também de importância capital no material apresentado são as mudanças na abordagem terapêutica necessárias para lidar com idosos com esse tipo de problemática, que incluem o papel do ambiente como cobertura protetora (inserção do acompanhante terapêutico - placement - e intervenção na família) e o atendimento em psicoterapia comsetting ampliado para fazer frente à demanda.

\section{Antisocial aspects in old age}

According to Winnicott, antisocial tendency etiology is an experience of deprivation that occurs during the fusion between instinctual and motor elements. These elements defusion impairs creative development of object relations and leads to an expression of aggressiveness. In this scenario, the antisocial tendency is expressed by an environmental disorder, through lies, theft, and destructivity. This article presents a clinical case of antisocial behaviors in an older person, describing the therapeutic setting for the treatment of such condition. Considering that old age often presents with physical decadence and instinctual decline, it also discusses the association between this life period and a deprivation expressed through multiple disorders that are usually understood as signs of mere senescence but could possibly signify the expression of an antisocial tendency.

Keywords: antisocial tendency, old age, psychotherapy, Winnicott.

\section{Les aspects anti-sociaux de la vieillesse}

Résumé : Selon Winnicott, la tendance antisociale résulte d'une privation qui se produit au moment où s'opère la fusion entre les éléments instinctuels et moteurs. La défusion de ces éléments entraine une perte dans le développement créatif des relations objectales et dans l'expression de l'agressivité. La tendance antisociale se manifeste par une perturbation de l'environnement, par le mensonge, le vol et la destruction. Cet article présente un cas clinique dans lequel des comportements antisociaux se sont apparu chez une personne âgée et comment s'est constitué le cadre thérapeutique de son traitement. Enfin, le texte propose une réflexion : cette étape de la vie, que l'on nomme vieillesse et qui se présente souvent comme une déchéance physique et un déclin instinctif, ne provoquerait-elle chez les individus une déprivation qui s'exprimerait par de multiples troubles, normalement perçus comme des manifestations de la simple vieillesse mais qui, en fait, pourraient être mieux compris comme l'expression d'une tendance antisociale?

Mots-clés : tendance antisociale, vieillesse, psychothérapie, Winnicott.

\section{Aspectos antisociales en la vejez}

Resumen: Según Winnicott, la tendencia antisocial tiene por etiología una deprivación, que ocurre cuando los elementos instintuales y motores se están fusionando. La escisión entre estos elementos tiene como resultado un perjuicio en el desarrollo creativo de las relaciones objetales y la expresión de agresividad. La tendencia antisocial se manifiesta como una perturbación en el entorno mediante la mentira, el robo y la destructividad. En este artículo se presenta un caso clínico en el que surgieron comportamientos antisociales en una persona mayor y cómo se constituyó el setting terapéutico. Por último, se discute si la etapa de la vida conocida como vejez, por su decadencia física y el deterioro instintual en general, no les causaría a los individuos una deprivación, la cual se expresaría en múltiples desórdenes de la vejez que podrían entenderse como la expresión de una tendencia antisocial.

Palabras clave: tendencia antisocial, vejez, psicoterapia, Winnicott.

\section{Referências}

Khan, M. M. R. (1991). Quando a primavera chegar: despertares em psicanálise clínica (C. S. Bacchi, Trad.). São Paulo, SP: Escuta.

Safra, G. (2006a). Tarefas ontológicas da maturidade: em busca do eixo axial. São Paulo, SP: Sobornost.
Safra, G. (2006b). Maturidade em face da cultura. São Paulo, SP: Sobornost.

Safra, G. (2006c). Maturidade e morte. São Paulo, SP: Sobornost.

Safra, G. (2006d). Maturidade: dramas e possibilidades. São Paulo, SP: Sobornost. 
Tizard, L. J., \& Guntrip, H. J. B. (1960). The middle age. London: George Allen And Unwin.

Winnicott, D. W. (1975). O brincar e a realidade (J. O. A. Abreu \& V. Nobre, Trad.). Rio de Janeiro, RJ: Imago.

Winnicott, D. W. (2000). Da pediatria à psicanálise: obras escolhidas (D. Bogomoletz, Trad.). Rio de Janeiro, RJ: Imago. (Trabalho original publicado em 1978)

Winnicott, D. W. (2000). Residential management as treatment for difficult children. In Deprivation and delinquency (pp. 54-72). New York: Routledge. (Trabalho original publicado em 1984)
Winnicott, D. W. (2012). Privação e delinquência (A. Cabral, Trad., 3a ed.). São Paulo, SP: Martins Fontes. (Trabalho original publicado em 1987)

Winnicott, D. W. (2005). Tudo começa em casa (P. Sandler, Trad., 4a ed.). São Paulo, SP: Martins Fontes. (Trabalho original publicado em 1989)

Recebido: $25 / 10 / 2020$

Revisado: $15 / 05 / 2021$

Aprovado: 23/06/2021 